\title{
Environmental implications of onsite mechanization in the Malaysian construction industry
}

\author{
M. Waris ${ }^{1}$, M. S. Liew ${ }^{1}$, M. F. Khamidi ${ }^{2}$ \& A. Idrus ${ }^{3}$ \\ ${ }^{I}$ Department of Civil Engineering, \\ Universiti Teknologi PETRONAS, Malaysia \\ ${ }^{2}$ Heriot-Watt University, Malaysia \\ ${ }^{3}$ Universiti Pertahanan Nasional Malaysia, Malaysia
}

\begin{abstract}
In Malaysia, there has been a growing need for mechanization in recent years due to the high construction demand under the Economic Transformation Programme. Onsite mechanization in construction implies the use of equipment and machinery that are powered by fossil fuels with the aim of reducing the dependency on manual labour and to increase productivity, quality and efficiency. However, this heavy equipment and machinery are also responsible for issues pertaining to environment, health and safety of human beings. All nonroad diesel engine machinery emits hazardous gases, particulate matters, solid waste and contaminate land, water and the environment. Prior research on environmental impacts of construction works was more focused on raw materials, its manufacturing and operational phase of the facility. Therefore, the aim of this research is to focus on environmental concerns that are important during construction and mainly due to the operation of onsite heavy construction equipment. Data for the analysis was collected through a questionnaire survey from Malaysian G7 class 'A' contractors. The results of the survey show that despite the good awareness of Malaysian contractors towards a green environment, their practices for controlling energy consumption and greenhouse gases (GHG) are still in their infancy stages. It was also found that environment management systems are not highly implemented by the contractors. The survey results further indicate that energy saving, GHG and black smoke emission are the top ranking concerns of contractors when operating onsite equipment and
\end{abstract}


vehicles. The research findings will help to begin efforts for adopting a cleaner and green agenda for sustainable construction.

Keywords: construction emissions, GHG pollution, mechanized construction.

\section{Introduction}

Construction activities are considered as important growth indicators for any progressive country. It has a pivotal role towards the whole society to actively engage them for the prosperity of the nation. Due to this, construction organizations are also seen as important social actors, and they are accountable for the impacts of an implemented project on the society, environment and economy long after the project has been completed. Construction organizations are responsible for the designing, planning, execution, operation and maintenance of housing. buildings, highways, airports, docks, harbor, irrigation systems, essential municipal services, structural work bridges, tunnels, dams, reservoirs, power stations etc. These construction projects are usually classified in to residential, commercial, industrial and heavy works [1]. All these projects required different types of equipment and machinery and have their own level of usage. For example residential projects have a light level of equipment use. It requires simple and traditional machines like fork-lifters, backhoe, hauling and hoisting equipment, material handling along with pneumatic tools. Commercial projects have moderate use of equipment and machinery. Industrial and heavy construction projects required intense and high utilization of machinery for carrying out mass excavation, stabilizing, compacting, asphalt paving and finishing, pipelines, railroads and many other special activities [2]. During project execution, onsite mechanized construction activities have significant impacts on the external environment. The emerging concept of sustainable or green construction has emphasized the elimination and minimization of harmful impacts to the environment. A large number of construction projects emerge on traditional planning approach and primarily focus on time and cost constraints rather than environmental issues that pose serious threats to the ecological system. Even a minor impact, such as a small release or spill of a hazardous substance, can cause a health or environmental threat and lead to costly cleanup activities [3]. Therefore, there is need for identification and prioritization of hazardous impacts that assists contractors for addressing them in a prompt manner. Hence, this study aims to determine environmental concerns that emerge due to the usage of heavy construction equipment and machinery.

\section{Onsite emissions and their hazardous effects}

The past studies have shown that environmental focus in construction was more on material selection, structure design, materials recycling rather than GHG emissions [4]. Furthermore, previous efforts to reach sustainability have primarily focused on the environmental performance of facilities in the "use" phase, and such efforts are lately being expanded to mitigate environmental impacts from the "construction" phase [5]. Among the environmental impacts 
from construction processes (such as waste generation, energy consumption, resource depletion, etc.), emissions from onsite construction equipment account for the largest share (more than 50\%) of the total impacts [6]. All non-road construction equipment, machinery and vehicles which are power-driven by diesel engine have a high impact on environment. The emissions from this equipment are considered as source of air pollution. The United States Environmental Protection Agency (EPA) stated that the US construction industry is comprised of approximately 2 million equipment, machinery and vehicles which are powered by diesel engine. These engines are operated by fossil fuel, hence discharge significant amount of carbon dioxide, hydrocarbons and particulate matter. EPA report further exemplifies that a road bulldozer with an engine capacity of $175 \mathrm{hp}$ releases particulate matter which is equal to the emissions produced by 500 new auto mobiles [7]. In United States, 5,839.3 million metric tons (MTs) of $\mathrm{CO}_{2}$ is produced by the usage of fossil fuels to operate heavy construction equipment in 2008 [8]. According to the Korean National Institute of Environmental Research (2009), air pollutant emissions from onsite construction equipment account for $6.8 \%$ (253, 058 MTs / year) of the overall emissions produced in Korea [9]. The average rate of production of emissions is much greater for construction equipment as compared to passenger vehicles because of differences in the fuel type i.e. diesel versus gasoline, engine technology and horse power [10]. Equipment categorization, age and horsepower and as well as type of fuel used, can greatly affect rates of emissions [11]. Based on the previous study, it was determined that during construction phase, earthwork produces highest percentage of GHG emissions [4].

Air pollutant emitted are dangerous for the ecological system and as well as for human beings. Due to the improper and incomplete combustion in the engine, the oxidation of the carbon monoxide $(\mathrm{CO})$ contained in the fuel mixture remain premature and it does not converted into to the Carbon dioxide $\left(\mathrm{CO}_{2}\right)$. In addition to this, inadequate amount of oxygen in the air/fuel mixture also elevates the formation of $\mathrm{CO}$. However, if a complete combustion is taken place in the engine, then relatively a low amount of $\mathrm{CO}$ is produced and exhaust in the atmosphere [12]. Carbon monoxide (CO) is a colorless, odorless and tasteless gas and it is a product of incomplete combustion and produced when carbon in the fuel mixture is partially oxidized rather than fully oxidized to carbon dioxide. It is considered a major source of $\mathrm{CO}$ in the atmosphere. The $\mathrm{CO}$ produced by gasoline engine is more than the diesel engine. As the lateral type of engines have air injectors which provide plenty of air for oxidizing the combustion mixture completely. Carbon monoxide has significant harmful health perspective as it retard the absorption of oxygen in the bloodstream by reacting with hemoglobin. It is principally dangerous for cardiovascular patients and may cause severe chest pain [7].

Nitrogen oxides $\left(\mathrm{NO}_{\mathrm{x}}\right)$ are formed due to the reaction of fuel mixture with air. Its percentage increases proportionally with the high flame temperatures in the presence of rich concentration of oxygen. The oxides of Nitrogen $\left(\mathrm{NO}_{\mathrm{x}}\right)$ emissions mainly comprises of Nitric oxide (NO) and Nitrogen dioxide $\left(\mathrm{NO}_{2}\right)$. $\mathrm{NO}$ is considered as major species contained in emissions and it is normally 
acknowledged to be a high proportion of the total $\mathrm{NO}_{\mathrm{x}}$ that exhaust in the atmosphere. It has been determined that high pressure and temperature expedite the reaction of nitrogen and oxygen atoms in the presence of air react and produce various nitrogen oxides, collectively known as $\mathrm{NO}_{\mathrm{x}}$. They are also considered a chief source of acidic rain and smog deposition. These products are harmful to human health, plants and animal. Furthermore, Nitrogen oxides when reacts with volatile organic compounds in the presence of sunlight forms photochemical oxidants including ozone. Ozone is harmful for ENT (Ear, Nose and Throat) problems in human and also causes pulmonary diseases. It has also irreversible effects on agriculture crops and deteriorates synthetic products like paint, rubber, textiles and other materials [13].

Apart from $\mathrm{CO}$ and $\mathrm{NO}_{\mathrm{x}}$, atmospheric particulate matters are miniature or fine pieces of solids and liquids that are exhausted into the atmosphere. It may also be formed in the external atmosphere as a reaction of exhaust emissions with atmospheric air. These particulates also pose serious threats to environment by producing smog, haze and other health concerns [14].

\section{Strategies for emission reduction}

The growing need of environmental concerns and legislations has led to adoption of emissions reduction techniques and safe operation of construction equipment and vehicles. Since the last decades of $20^{\text {th }}$ century, continuous efforts are underway in order to reduce exhaust emissions but it seems that the real outcome is still far away. Usually, it has been considered that green practices are much expensive and require sufficient amount of budget for practicing effectively. A large capital investment is required for retrofitting and changes the equipment for meeting green specifications. Along with, the cost of using alternative fuel such as bio-diesel or low sulfur fuel is another financial issue. It is an extra financial burden for small and medium size construction companies which may not be able to bear. Furthermore, the normal operating life of non-road diesel equipment and machinery are between 20 to 30 years. New emissions standards are typically not met by old and existing equipment. Therefore, the impacts of such changes are likely to be felt and majority of aged equipment are replaced by equipment meeting newer and more stringent regulations. In United States, private sector is considered to be the owner of 90 percent of non-road diesel vehicles and diesel engines. So, private sector is a key stakeholder in controlling the change and its pace for meeting new standards and regulations. Thus, it is obligatory that private sector should facilities for a change ahead of natural equipment turnover rates may help make diesel emission reductions in the near future.

In view of the above, the United States Environmental Protection Agency (EPA) has emphasized the adoption of emission reduction practices by offering certain incentives to the operators [11]. In this context, EPA has launched Voluntary Diesel Retrofit Program, Carl Moyer Program and Texas Emissions Reduction Plan which are noteworthy incentive programs in order to reduce the GHG emissions. Under these programs, operators of the construction equipment 
are encouraged and offered incentives to adopt environmental friendly practices for achieving low carbon emissions. These incentives were offered for those operators who promote the use of exhaust treatment devices, reduce idling time, upgrade their engines, use ultra low sulphur, bio-degradable fuel and keep their equipment in good working condition [15].

The Dutch Government has introduced sustainable criteria for the procurement of heavy duty equipment and vehicles. This criterion embarks procedures and guidelines for ensuring green practices in hiring, operation and maintenance of non-road vehicles and equipment [16]. The precedent research shows that the proper selection of construction equipment and machinery can also be helpful to reduce GHG emissions. As GHG emissions are directly related to the operation of equipment, the more the operating hour of machinery, the higher the energy consumption and hence more will be the rate of emissions [4].

In the broader perspective, it can be stated that the control of exhaust emissions from the non-road diesel engines can benefit the whole society in terms of healthiness and provide them a safer and clean environment to live-in.

\section{Research objective}

This paper aims to determine the environmental concerns that have relative importance with respect to the operation of onsite non-road diesel vehicles and construction equipment. It also investigates the current state of practices for controlling and reducing the GHG emissions in Malaysian construction industry.

\section{Methodology}

The desired research objectives were achieved through a structured questionnaire. The close ended questionnaire was designed and sent to the Grade G7 civil contractors of Malaysia (Kuala Lumpur and Selangor based). A total number of 400 contractors were randomly selected from Construction Industry Development Board (CIDB) of Malaysia database. According to CIDB, civil contractors are categorized into seven classes. Among them, G7 are large contractors and usually engaged in heavy and complex construction activities with no limit. Hence, they are considered to be more equipped with the non road diesel vehicles, heavy equipment and machinery. According to the Master Builder Association of Malaysia (MBAM) survey that despite a high percentage of contractors in Malaysia, only $12 \%$ are actually running construction business [17]. Therefore, before sending the questionnaire to the respondents, it was dully confirmed and assured that all the targeted respondents should be engaged in heavy civil and infrastructure works. The survey questionnaire is consisted of two sections. Section I has asked about the general and demographic information of contractors whereas Section II is about environmental concerns for achieving green construction. A sample questionnaire is provided in the appendix. 


\section{Results and analysis}

The data collected from the questionnaire survey was analyzed by using SPSS software. After repetitive follow-ups, a total number of 86 completed feedbacks were received from the targeted respondents. This makes an overall response rate of $21.5 \%$ which is good enough for research findings. The past research shows that the outcome of a postal survey in construction industry is usually in the range of 20-30 percent [18, 19]. Hence, the current percentage of feedbacks is good enough for analysis. The findings of the survey are discussed in the next section;

\subsection{Respondents' profile and background}

The responses were received from a diversified group of industry professionals. It include $35 \%$ project managers, $27 \%$ managers, $19 \%$ quantity surveyors, $11 \%$ engineers, $7 \%$ construction managers and $1 \%$ equipment manager. It has been found that project managers have a high level of participation in this survey. Fig. 1 shows the bar chart of respondents.

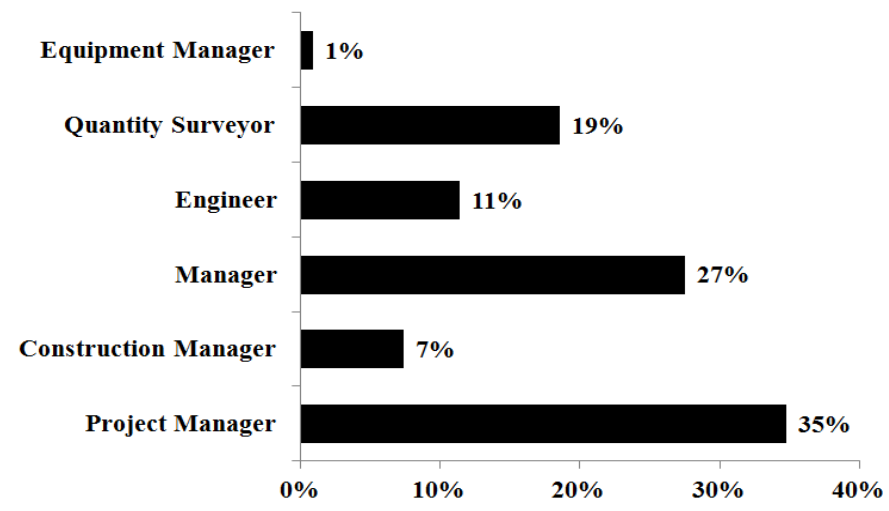

Figure 1: $\quad$ Bar chart of respondents primary job function.

These survey statistics represents that responses are mostly received from the experienced and senior professionals having vast experience in construction and infrastructure projects. It includes $31.5 \%$ of responses from professionals having working experience within the range of 11 to 20 years, while $22.6 \%$ have more than 20 years of field experience. The respondents whose working experience is between 6 to 10 years are $21 \%$. Rest of the $25 \%$ respondents has less than 5 years' experience in construction projects. Hence, their opinions and views are quite important and reliable in order to establish the findings. The result of the survey also stated that $88 \%$ of the respondents have completed their bachelor's education. Some of the respondents have also acquired additional postgraduate qualifications i.e. MSc and Master degree with a percentage of $3.25 \%$ and $4.8 \%$ respectively. This reveals that the respondents have a good academic background 
and satisfactory knowledge for providing sufficient details and inputs for the outcome of this research work.

\subsection{Adoption of Environmental Management System}

An Environmental Management System (EMS) is a tool and represents an organization's environmental concerns to sustain compliance with environmental regulations, reduce hazardous risks, train employees, develop indicators of impact and improve environmental performance. An EMS typically consists of policies, goals, information systems, task lists, data collection and organization, emergency plans, audits, regulatory requirements, and annual reports. The results of the survey show that EMS adoption is still in rare in Malaysian construction industry. Fig. 2 shows the level of EMS adoption. The data shows that only $21 \%$ are practicing ISO $14001 / 1404,9.7 \%$ ISO $1901,1.6 \%$ BS 8900 and only $0.8 \%$ ISO 14024.

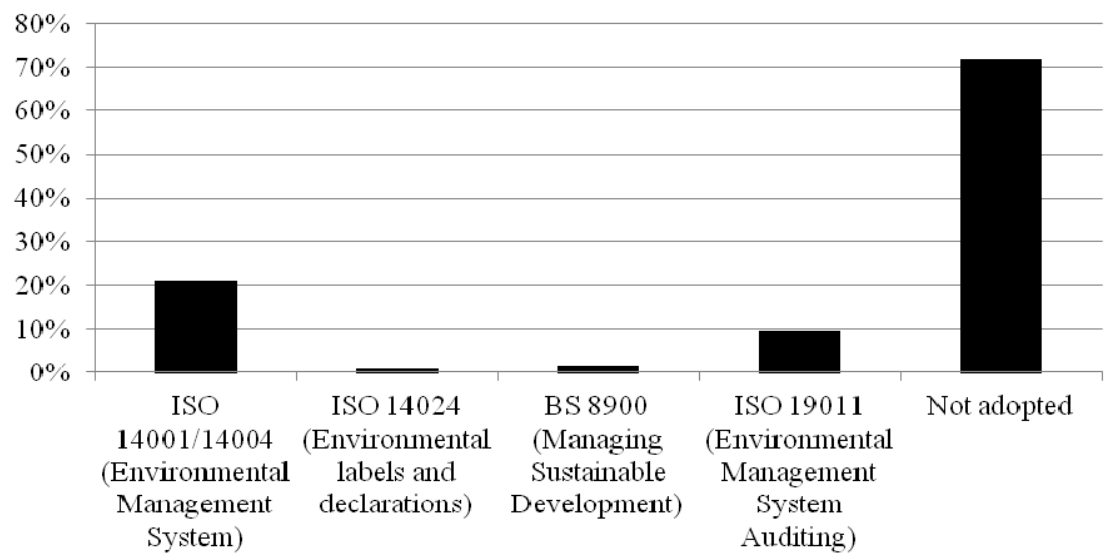

Figure 2: $\quad$ Adoption of EMS in the Malaysian construction industry.

\subsection{Calculation of GHG emissions}

Onsite construction activities are considered for generating air pollution in terms of GHG emissions. It is therefore pertinent to assess the emissions from non-road diesel and gasoline engines deployed on the construction site. The GHG estimates from various equipment involved in construction activities help to analyze the thresholds level and subsequent measures for their control. The survey results indicate that only $7 \%$ of the respondents are measuring GHG emissions, whereas $77 \%$ of the respondents are not applying any tool or method for the calculation of GHG. The GHG calculation is the basic premise for emission reduction planning. Table 1 shows the respondents' feedback regarding calculation of GHG emissions. 
Table 1: GHG emissions calculations.

\begin{tabular}{|c|c|c|}
\hline S. No. & GHG calculation & Percentage \\
\hline 1 & Yes & $7 \%$ \\
\hline 2 & No & $77 \%$ \\
\hline 3 & Don't Know & $16 \%$ \\
\hline \multicolumn{2}{|c|}{ Total } & $100 \%$ \\
\hline
\end{tabular}

\subsection{Energy planning of onsite construction equipment}

Energy consumption during construction activities are directly related to the GHG emissions. The higher the fuel/energy consumption, the more will be the exhaust emissions. The survey results indicate that energy planning of onsite construction equipment is moderately practiced by the respondents. Only $35 \%$ respondents are calculating energy consumption of onsite machinery. Fig. 3 shows their distribution in percentages.

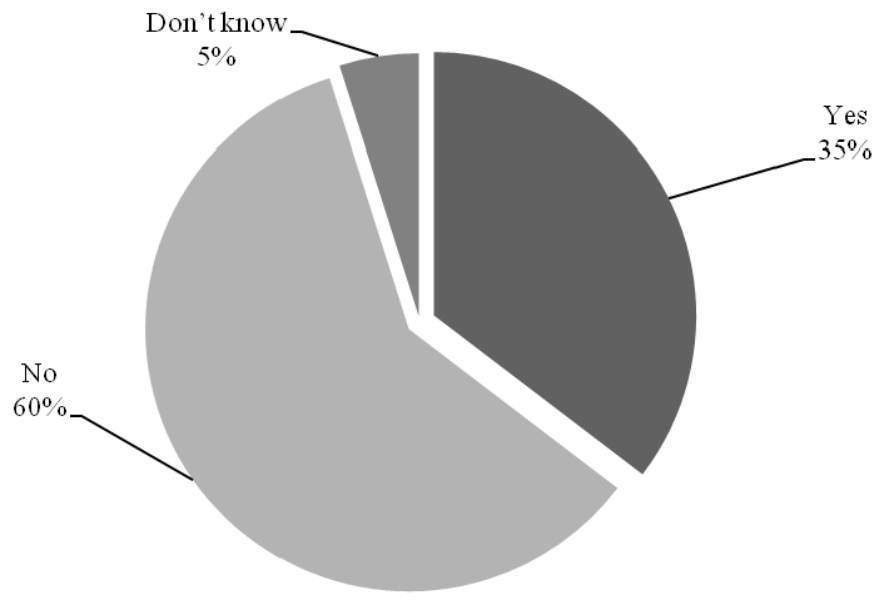

Figure 3: $\quad$ Calculation of energy consumption of onsite equipment.

\subsection{Environmental concerns onsite construction equipment}

The operations of heavy construction equipment pose serious concerns to the environment. Past research shows a number of environmental implications due to the usage of heavy construction equipment. Hence, their level of importance in the Malaysian construction industry is evaluated through this research study. This study has used 5-point Likert scale (with $1=$ No importance, $2=$ Low importance, 3 = Neutral, $4=$ Very important and $5=$ extremely important) to measure the priorities of respondents towards environmental issues. The purpose 
of Likert ranking is to facilitate respondents to express the direction and strength of opinion on the statements in the questionnaire. The use of 5-point Likert scale was considered appropriate because it increases the reliability of the measure, reducing social desirability and biasness among respondents. It also helps them to be aware with the phenomenon under study and given the option to typically skip the scale in the case of ambiguity, and has been used by previous researchers. The reliability of 5-point Likert scale was determined by using Cronbach's alpha coefficients. Ideally, the Cronbach alpha coefficient of a reliable scale should be greater than 0.70 [20]. A reliability test for the fourteen sustainable practices (as shown in Table 2) was conducted by using the SPSS software. The Cronbach alpha for the used Likert scale is 0.908 . This indicates that the data collected for the analysis is interrelated and consistent. Table 2 shows the mean score, rank and average index assessment indicator for the environmental implications of onsite construction equipment [21].

Table 2 shows the "High" impact environmental concerns that are produced from the non-road diesel engine equipment and vehicles. It indicates that energy consumption, GHG, black smoke emissions are the top ranking concerns that are inherent with the onsite operation of construction equipment.

Table 2: Mean score, rank and average index assessment.

\begin{tabular}{|l|c|c|c|}
\hline $\begin{array}{c}\text { Environmental } \\
\text { implications }\end{array}$ & $\begin{array}{c}\text { Overall mean } \\
\text { score }\end{array}$ & Rank & $\begin{array}{c}\text { Average index } \\
\text { (indicator) }\end{array}$ \\
\hline Energy consumption & 4.18 & 1 & High \\
\hline Greenhouse gas emissions & 4.13 & 2 & High \\
\hline Black smoke emissions & 4.09 & 3 & High \\
\hline Lead emissions & 4.04 & 4 & High \\
\hline Noise emissions & 4.01 & 5 & High \\
\hline Dust pollution & 3.99 & 6 & High \\
\hline Vibration & 3.94 & 7 & High \\
\hline
\end{tabular}

\section{Conclusion}

The study has investigated that the environmental implications of onsite heavy construction equipment in Malaysian construction industry. The findings of this study show that there is growing recognition towards the implementation of EMS. This is considered as a positive step for the minimization of harmful environmental impacts from construction. However, its implementation is still in infancy stages. The results further indicate that energy consumption, GHG and black smoke emissions are top ranking hazardous but they are not widely been monitored and calculated during onsite construction activities. Hence, it is imperative that construction industry must raise its level of implementation for green practices and particularly with respect to the control of onsite air pollutions emissions. 


\section{Appendix}

\section{Section I: background and general information}

Please fill in the blanks and tick $[\sqrt{ }]$ in the options as provided.

1. Name of Company:

2. Position in Company:

$\left[\begin{array}{l}\text { [ Project Manager [ } \\ {[\quad] \text { Construction Manager [ ] }}\end{array}\right]$ Manager
$[\quad]$ Equipment Manager [ ] Quantity Surveyor

3. Respondent's experience in construction projects? __ (Years) (Months)

4. Please mention your level of education:

[ ] Bachelor [ ] MSc/MBA//Master [ ] PhD [ ] Others

5 . What is the size of your organization you work in?
[ ] $<100$ staff [ ] 101-250 staff
] 251-500 staff
[ ] $>500$ staff

6. Your experience in infrastructure projects?

(Years) (Months)

\section{Section II: environmental concern}

7. Please indicate the adopted standard in your company?

[ ] ISO 14001/14004 (Environmental Management System)

[ ] ISO 14024 (Environmental labels and declarations)

[ ] BS 8900 (Managing Sustainable Development)

[ ] ISO 19011 (Environmental Management System Auditing)

[ ] Not adopted

8. Do you calculate energy consumption of different mechanized equipment during onsite construction activities?

[ ] Yes [ ] No [ ] Don't know

9. Do you apply any tool or method to calculate greenhouse gas emissions from different onsite equipment usage?

[ ] Yes [ ] No [ ] Don't know

10. Please indicate your opinion on a 5 point Likert scale about the importance of environmental concern due to the usage of onsite construction equipment.

\begin{tabular}{|l|c|c|c|c|c|}
\hline \multirow{2}{*}{ Descriptions } & \multicolumn{2}{|c|}{ Extremely Important } & \multicolumn{2}{c|}{ No Importance } \\
\cline { 2 - 6 } & $\mathbf{5}$ & $\mathbf{4}$ & $\mathbf{3}$ & $\mathbf{2}$ & $\mathbf{1}$ \\
\hline $\begin{array}{l}\text { Greenhouse gas } \\
\text { emissions }\end{array}$ & & & & & \\
\hline Noise emissions & & & & & \\
\hline $\begin{array}{l}\text { Energy } \\
\text { consumption }\end{array}$ & & & & & \\
\hline $\begin{array}{l}\text { Black smoke } \\
\text { emissions }\end{array}$ & & & & & \\
\hline Vibration & & & & & \\
\hline Dust pollution & & & & & \\
\hline Lead emissions & & & & & \\
\hline
\end{tabular}




\section{References}

[1] Knutson, K., Schexnayder, C.J., Fiori, C. \& Mayo, R., Construction Management Fundamentals, McGraw-Hill, New York, 2009.

[2] Gransberg, D.D., Popescu, C.M. \& Ryan, R.C., Construction Equipment Management for Engineers, Estimators and Owners, Taylor \& Francis, New York, 2006.

[3] Hendrickson, C.T. \& Horvath, A., Resource use and environmental emissions of U.S. construction sectors, Construction Engineering and Management, 126(1), pp. 38-44, 2000.

[4] Kim, B., Lee, H., Park, H. \& Kim, H., Greenhouse gas emissions from onsite equipment usage in road construction, Construction Engineering and Management, 138(8), pp. 982-990, 2012.

[5] Peña-Mora, F., Ahn, C., Golparvar-Fard, M., Hajibabai, L., Shiftehfar, S., An, S., Aziz, Z. \& Song, S.H., A framework for managing emissions during construction." Proc., Int. Conference and Workshop on Sustainable Green Building Design and Construction, National Science Foundation, Cairo, Egypt, 2009.

[6] Guggemos, A. A. \& Horvath, A., Decision-support tool for assessing the environmental effects of constructing commercial buildings, Architectural Engineering, 12(2), pp. 87-195, 2006.

[7] Lewis, P., Rasdorf, W., Frey, H., Pang, S. \& Kim, K., Requirements and incentives for reducing construction vehicle emissions and comparison of nonroad diesel engine emissions data sources, Construction Engineering and Management, 135(5), pp. 341-351, 2009.

[8] Emissions of Greenhouse Gases in the United States; U.S. Energy Information Administration (USEIA), Washington DC, 2009.

[9] Civil Engineering Cost Data; Korea Institute of Construction Technology, Gyeonggi-do, Republic of Korea, 2010.

[10] Heavy-Duty Engine Emissions in the Northeast; Northeast States for Coordinated Air Use Management, Boston, 1997.

[11] Avetisyan, H., Miller-Hooks, E., and Melanta, S., Decision models to support greenhouse gas emissions reduction from transportation construction projects, Construction Engineering and Management, 138(5), pp. 631-641, 2012.

[12] Shuhaili, A., Fadzil, A., Izan, I.S. \& Fekry, F.W., Air pollution study of vehicles emission in high volume traffic: Selangor, Malaysia as a case study, World Scientific and Engineering Academy and Society, 12(2), 2013.

[13] Seinfeld, J.H. \& Pandis, S.N., Atmospheric chemistry and physics: from air pollution to climate change, Wiley-Interscience, N.J. 1998.

[14] Cooper, C.D. \& Alley, F.C., Air pollution control: a design approach, Waveland Press, Inc.IL, 1994.

[15] Bailey, K., Emission reduction incentives for off-road diesel equipment used in the port and construction sectors, ICF Consulting, Virginia, 2005. 
[16] Criteria for the sustainable procurement of heavy-duty motor vehicles and mobile equipment including maintenance services, Dutch Ministry of Infrastructure and the Environment 2011.

[17] Bahaman, A.T.S., The key issues in the Malaysian construction industry: public and private sector engagement, Master Builders Association Malaysia, Penang, 2011.

[18] Akintoye, A., Analysis of factors influencing project cost estimating practice, Construction Management and Economics, 18(1), pp. 77-89, 2000.

[19] Dulami, M.F., Ling, F.Y.Y. \& Bajracharya, A., Organizational motivation and inter-organizational interaction in construction innovation in Singapore, Construction Management and Economics, 21(3), pp. 307-318, 2003.

[20] Iarossi, G., The power of survey design: a user's guide for managing surveys, interpreting results, and influencing respondents, World Bank, Washington DC, 2006.

[21] Majid, A., Assessment of work performance, $\mathrm{PhD}$ dissertation, Loughborough University, UK, 1997. 